\title{
Assessment of survival in retrospective studies: The Social Security Death Index is not adequate for estimation
}

\author{
Sven Peterss, MD, ${ }^{\mathrm{a}, \mathrm{b}}$ Paris Charilaou, MD, ${ }^{\mathrm{a}, \mathrm{c}}$ Bulat A. Ziganshin, MD, ${ }^{\mathrm{a}, \mathrm{d}}$ and John A. Elefteriades, MD,
} New Haven, Conn; Munich, Germany; New Brunswick, NJ; and Kazan, Russia

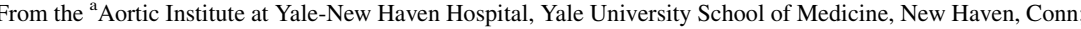
${ }^{\mathrm{b}}$ Department of Cardiac Surgery, University Hospital Munich, Ludwig Maximilian University, Munich, Germany; ${ }^{\circ}$ Department of Internal Medicine, Rutgers/Saint Peters University Hospital, New Brunswick, NJ; and ${ }^{\mathrm{d}}$ Department of Surgical Diseases \#2, Kazan State Medical University, Kazan, Russia.

Dr Sven Peterss is supported by a research fellowship (PE 2206/1-1) of the Deutsche Forschungsgemeinschaft (DFG), Bonn, Germany.

Disclosures: Authors have nothing to disclose with regard to commercial support.

Received for publication April 26, 2016; revisions received July 17, 2016; accepted for publication Sept 8, 2016; available ahead of print Oct 14, 2016.

Address for reprints: John A. Elefteriades, MD, Aortic Institute at Yale-New Haven Hospital, Yale University School of Medicine, Clinic Building CB317, 789 Howard Ave, New Haven, CT 06510 (E-mail: john. elefteriades@yale.edu).

J Thorac Cardiovasc Surg 2017;153:899-901

$0022-5223 / \$ 36.00$

Copyright $\odot 2016$ by The American Association for Thoracic Surgery

http://dx.doi.org/10.1016/j.jtcvs.2016.09.014
}

Survival is an important outcome measure of successful treatment in medical research. Survival is predominantly analyzed by Kaplan-Meier estimation and requires two data points: status (deceased or alive) and delta time. In retrospective studies and studies with large populations, the Social Security Death Index (SSDI), based on the Social Security Administration's Death Master File, is an established and inexpensive method to evaluate the current status of patients and to close gaps during follow-up. This study aims to compare the SSDI methodology with our institutional multimodal methodology (Aortic Institute Methodology [AIM]).

\section{PATIENTS AND METHODS \\ Study Design}

Five recent retrospective studies from our institute including aortic and aortic valve diseases, treated between 2000 and 2015, were merged, and survival follow-up was assessed and compared using two different methods for each patient (SSDI query [December 2931, 2015] vs our multimodal Aortic Institute Methodology [AIM; April 2014 to December 2015]). Only US citizens and patients who had a Social Security Number (SSN) were included. The Human Investigation Committee of Yale University approved this retrospective study.

Follow-up of the SSDI group was achieved using the online available open source Death Master File of the Social Security Administration. ${ }^{1,2}$ The query entry items included SSN and name and date of birth ( \pm 1 day). The status "alive" was set as of the date of the query.

The AIM for retrospective studies is based on the following sequential steps:

1. An online database query, available from free websites such as SSDI query ${ }^{1}$ and MooseRoots.

2. A hospital IT system query (Epic Hyperspace 2015, Epic Systems Corporation), compiling information from former charts, linked

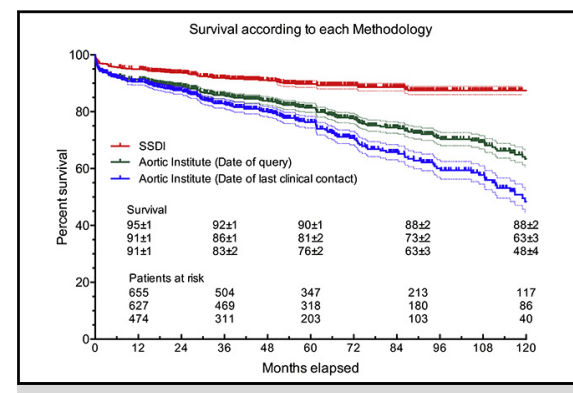

Survival is significantly affected by methodology.

Central Message

Survival estimation by SSDI is inferior to multimodal follow-up assessments and estimates differ significantly between the methods. SSDI is not suitable as a sole method of survival analysis.

See Editorial Commentary page 902

TABLE 1. Demographic characteristics and operative data

\begin{tabular}{|c|c|c|}
\hline Variable & Frequency/mean & $\%$ \\
\hline $\mathrm{N}$ & 698 & \\
\hline Age (y) & $66.2 \pm 14.4$ & \\
\hline Male gender & 432 & 61.9 \\
\hline \multicolumn{3}{|l|}{ Predominantly disease } \\
\hline Isolated valve disease & 160 & 22.9 \\
\hline Aortic aneurysm & 390 & 55. \\
\hline Acute type A dissection & 148 & 21.2 \\
\hline Bicuspid morphology & $240 / 677$ & 35.5 \\
\hline \multicolumn{3}{|l|}{ Comorbidities } \\
\hline Marfan & 6/696 & 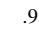 \\
\hline Smoking & $175 / 533$ & 32.8 \\
\hline Coronary artery disease & $122 / 696$ & 17.5 \\
\hline LVEF (\%) & $56.9 \pm 10.7$ & \\
\hline COPD & $81 / 696$ & 11.6 \\
\hline Renal failure (chronic) & 59 & 8.5 \\
\hline Hemodialysis & $2 / 696$ & 0.3 \\
\hline Diabetes & $78 / 548$ & 14.2 \\
\hline Dyslipidemia & $305 / 548$ & 55.7 \\
\hline Arterial hypertension & $552 / 696$ & 79.3 \\
\hline Pulmonary hypertension & $43 / 533$ & 8.1 \\
\hline Status after stroke & $35 / 697$ & 5.0 \\
\hline \multicolumn{3}{|l|}{ Operative data } \\
\hline Previous cardiac surgery & 86 & 12.3 \\
\hline \multicolumn{3}{|l|}{ Proximal thoracic aorta/valve } \\
\hline Isolated AVR & 159 & 22.8 \\
\hline Root replacement/Bentall procedure & 95 & 13.7 \\
\hline Root-sparing ascending replacement & 444 & 63.6 \\
\hline With AVR & 258 & 37.0 \\
\hline \multicolumn{3}{|l|}{ Distal thoracic aorta } \\
\hline Arch replacement & 49 & 7.0 \\
\hline Elephant trunk stage I & 31 & 4. \\
\hline
\end{tabular}

Data are shown as frequency and percentage, mean \pm standard deviation, or as reported. $L V E F$, Left ventricular ejection function; $C O P D$, chronic obstructive pulmonary disease; $A V R$, aortic valve replacement. 
TABLE 2. Performance measure data

Total True positive True negative False negative False positive

\begin{tabular}{lllll}
\hline 698 & 73 & 527 & 98 & 0 \\
\hline
\end{tabular}

Data are shown as frequency.

physicians/hospitals, and the Death Master File provided by the State of Connecticut.

3. Follow-ups by the clinical office or referring doctor.

4. Overriding sources (according to study design): (1) follow-up/ quality-of-life updates for specific research observations (by phone or questionnaire) and (2) an online obituary search.

5. Last proven clinical contact is set as status "alive."

\section{Study Population}

The study population included 698 patients $(61.9 \%$ male $)$ with a mean age of $66.2 \pm 14.4$ years. One hundred and sixty patients $(22.9 \%)$ had predominantly aortic valve pathology, 390 patients $(55.9 \%)$ had ascending aortic aneurysm disease, and 148 patients (21.2\%) had acute aortic dissection type A. Further demographic characteristics and operative data are shown in Table 1.

\section{Statistics}

Performance measures were analyzed by comparing the SSDI method with the AIM method. Survival difference according to methodology was estimated by Kaplan-Meier survival estimation and compared using the Mantel-Cox log rank test. The prevalence-independent measure, the negative likelihood ratio ( $-\mathrm{LR}$ ), was computed; a lower value implies a greater chance a death truly did not occur.

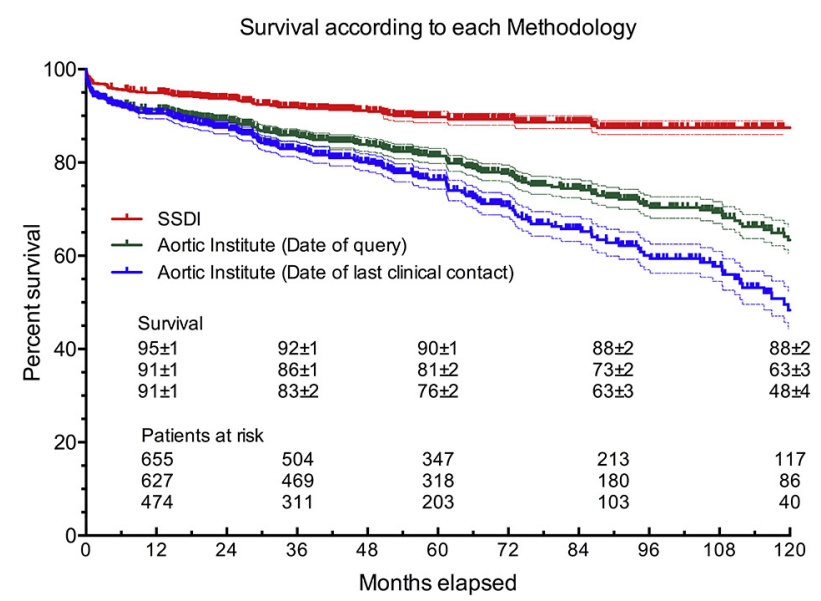

FIGURE 2. Kaplan-Meier survival estimation analyzing the identical population but using different follow-up methodologies. SSDI survival is estimated using the date of the query as status "alive." The AIM methodology is presented with both the date of the query and the date of the last proven contact as status "alive." SSDI, Social Security Death Index.

\section{RESULTS \\ Identified Patients}

The numbers of deceased patients who were identified according to each method are shown in Figure 1. The performance measures of the SSDI (compared with the

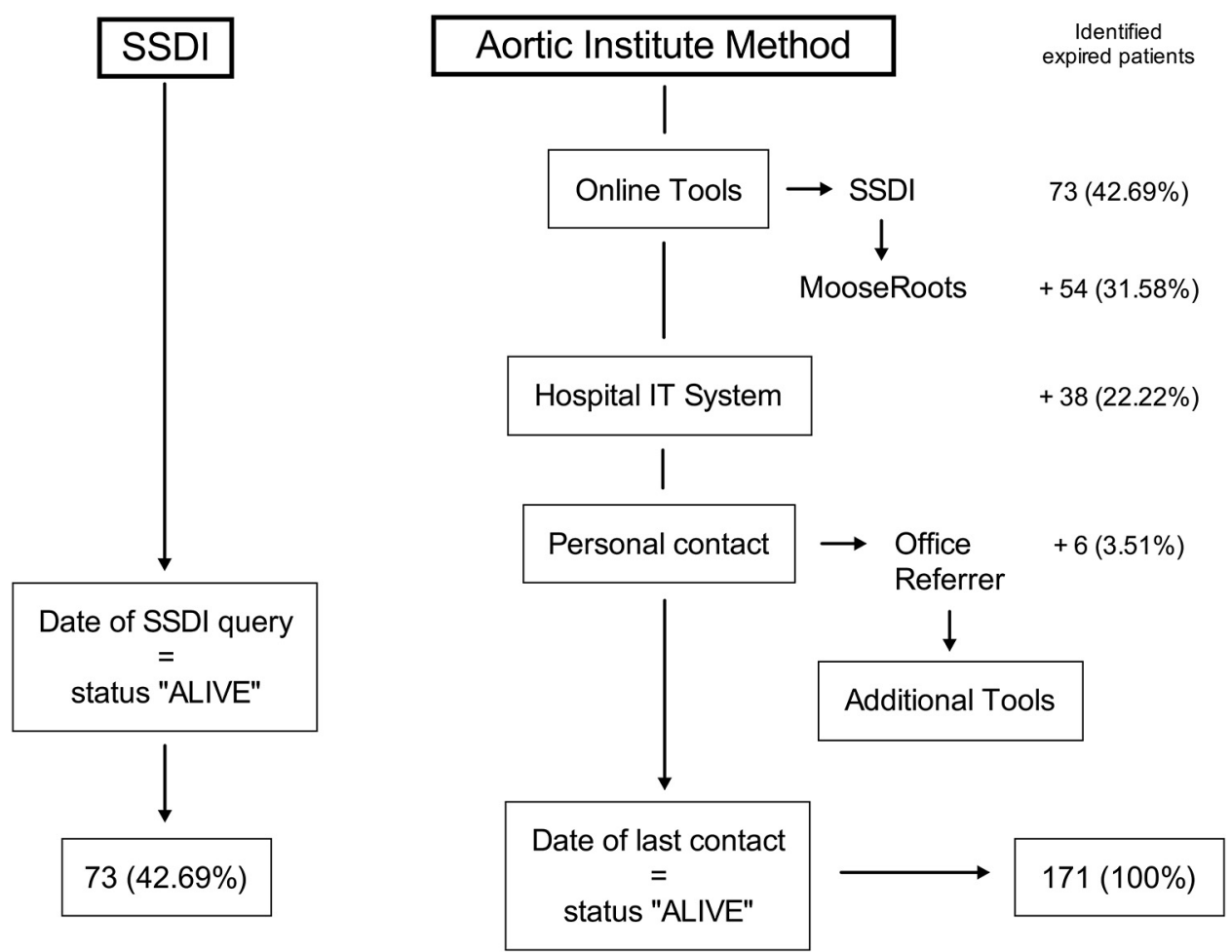

FIGURE 1. Number of deceased patients identified according to each methodology. The institutional method is transitioned, evaluating the non-expired patients by descending order of steps. SSDI, Social Security Death Index. 
AIM) were as follows (95\% confidence interval [CI]): (1) sensitivity, $42.7 \%(35.1 \%-50.5 \%)$ and (2) $-\mathrm{LR}$, $57.3 \%(50.4 \%-65.2 \%)$ (Table 2$)$.

Excluding patients who died within the barred years (2013-2015), the performance measures were as follows (95\% CI): (1) sensitivity, 58.4\% $(49.3 \%-67.1 \%)$ and (2) - LR, $41.6 \%(33.8 \%-51.2 \%)$.

Specificity was $100 \%$ throughout.

\section{Survival and Length of Follow-up}

The survival estimates, determined with the two methodologies for the same patients, differed significantly $(P<.0001)$ (Figure 2). The mean follow-up times were as follows: SSDI, $70.0 \pm 46.9$ months; AIM (query status "alive"), $63.1 \pm 44.9$ months; and AIM (clinical contact status "alive"), $42.6 \pm 42.9$ months.

\section{DISCUSSION}

In the present era, a multimodal assessment of survival estimation is significantly superior to sole use of SSDI open sources. The SSDI was formerly supplied by federal and state sources, but since November 2011 death information received from the states was not made public. ${ }^{4}$ Also, legislative rules governing the SSDI have changed, so that records from the most recent 3-year period are not available through publicly accessible free online services. ${ }^{5}$ Negative LRs, which are not affected by the prevalence of the outcome (ie, death, which can vary proportionally with age), were $57.3 \%$ for the total timeframe and $41.6 \%$ excluding the barred period, indicating that currently the SSDI fails to detect death adequately. The National Death Index by the Centers for Disease Control and Prevention could be an alternative source of survival data besides the described multimodality follow-up; however, it is a costly resource and time delayed. ${ }^{4}$

Above and beyond the methodology, the date of status "alive" significantly affects estimated survival. Although using the query date overestimates survival, the date of the last proven contact may underestimate it, even if the data are more solid. The real survival will most likely be between those curves, and close to the "last proven contact" curve.

Moving, change of contact data, and international patients (excluded) are the limiting factors of such multimodular methodology; however, using the last clinical contact as status "alive" diminishes such limitations.

We conclude that the sole use of the SSDI feigns a better survival and, thus, is not adequate for survival estimation in medical studies.

\section{References}

1. Genealogybank.com. Social Security Death Index SSDI records search. Available at: http://www.genealogybank.com/explore/ssdi/all. Accessed March 27, 2016

2. National Technical Information Service. Social Security Administration-death master file. Available at: http://www.ntis.gov/products/ssa-dmf/.

3. MooseRoots. Death records. Available at: http://death-records.mooseroots.com/. Accessed March 27, 2016.

4. Blackstone EH. Demise of a vital resource. J Thorac Cardiovasc Surg. 2012;143: 37-8.

5. Restriction on Access to the Death Master File. Pub L No. 67 (March 26, 2014). 